\title{
Manage the Barriers to the Control and Prevention of Hepatitis B in the Community
}

\author{
Rukhsana kausar \\ The University of Lahore main campus Lahore
}

\begin{abstract}
Hepatitis B virus, the most infectious health burden worldwide. Significant HBV in community. HBV infection is prevailing all around rapidly. Factors to proceed HBV. Poor cognition regarding hepatitis B, undeveloped education about health care, severe stigma in society, and also the unsatisfactory medical services. Barriers : Lack of proper diagnosis and treat due to the lack of awareness about it ,lack of health care providence Conclusion: Improvement in education about health services and treatment can make this all better and this may be achievable through well organized and targeted community based screening and educational interventions.
\end{abstract}

Keywords: Hepatitis-B-Virus (HBV), cirrhosis and hepatocellular carcinoma (HCC)

DOI: $10.7176 / \mathrm{JMPB} / 62-06$

Publication date: December $31^{\text {st }} 2019$

\section{Introduction}

HBV infection is prevailing around rapidly [1] [2]. Chronic HBV can be detected by the presence of an antigen (HBeAg) for six months in the blood or serum [3] [4]. In most people it is not very severe. In fact it does not create significant health problem but in some cases it proceeds to the liver fibrosis, cirrhosis and hepatocellular carcinoma (HCC) [5].

HBV is associated with the liver disease by the HBV DNA level in the blood. If the treatment like any antiviral treatment is not done, the cirrhosis may range from $8 \%$ to $20 \%$ [6] [7]. In cirrhosis, the decompensated liver disease have to face if remain untreated. In this way only $15 \%$ people can survive within five years in cirrhosis. Chronic hepatitis B based on the presence or absence of antigen is divided into two (HBeAg) positive or $\mathrm{HBeAg}$ negative. $\mathrm{HBeAg}$ is highly associated with the increased viral replication and so the increased effectivity. The main achievement is to prevent from cirrhosis, HCC and liver failure .On many scales surrogate markers are used to monitor the treatment response and the proceeding of this disease, and it includes in decrease in the inflammation

With no improvement on liver biopsies in fibrosis, making normal the serum alanine aminotransferase level, lacking serum HBV, DNA to un-detachable levels [8]. It may include the conversion from $\mathrm{HBeAg}$ to $\mathrm{HBe}$ antibody and the loss from HBsAg to HBs antibody.

When the adults experience the acute hepatitis B at the time of initial infection they face many conditions like anorexia, nausea, vomiting, and mostly the jaundice. It is approximately 30 to $50 \%$ in adults and 30 to $90 \%$ in children and infants and less from all above 2 to $6 \%$ among adolescents the chronic infection will may vary [9].

There is no confirmation of the liver disease in the persons with the chronic HBV infection and its high level of replication in the liver cells ( hepatocytes) does not happens in spite the remaining have the hepatitis ,(mild, moderate or severe) which lead the HCC and cirrhosis .There is $15 \%$ to $25 \%$ lifetime risk of death from chronic liver disease . Chronic infection ratio fluctuate according to the age [10].

\footnotetext{
Methodology

To know about the hepatitis in the community, many patients with HBV were collected. And the same people living in that community. And the health care providers. And also they reached to the people wished to be interviewed. For this a hospital, health services communities, offices of controlling the diseases and other nongovernmental organizations (NGO) were contacted. The participants showed the complete consent that they desired to be interviewed and met the criteria needed for interview. CDC employee were leading the prevention programmes. This interview got the appreciation due to its much extensive literature broadcasting. The questions asked were about the basic introductions by name, age, work, ailment, and cure, the situation present and the resistance creating for the disease overcome. A single hepatitis patient with a resident of community was interviewed by a single health service doctor before the actual interview. Two mainly experienced interviewers run the whole interview. One female was recording the main points and the interview was headed by a male researcher. As per individual the interviews were taken separately to avoid any confusions. The data taken by the interviews was for the purpose of research. The interviews were 20-40 minutes longer. When maximum data for research was collected the interview stopped. A framework theme created for the research by team. The recorded texts were translated into English by the person who could use the proficient English . The research work was appreciated by the medical universities.
} 


\section{Significant Environment Hepatitis B Virus}

The prevention services, treatment, care is needed to overcome the early identification of HBV. Further knowledge is as added after the research about access to vaccination, and the awareness of HBV among people and also the prevention from the delivery of this virus. Hepatitis B screening programmes were started in USA to overcome this virus. There are many other un- identified HBV carriers exist which may remain in higher ratio. The testing ratio of HBV is less in Asian, and in audition, the vaccination also. The chemotherapy is also induced for its treatment. Another thing all the patient who had hepatitis in past can prevent from its reactivation by an antiviral prophylaxis which is recommended. This will lower the risk of HBV reactivation for the people which are undergoing chemotherapy. This can prevail in different ages. Educational awareness is the main need of this issue.

\section{Factors to proceed HBV}

Certain factors are there disseminator of this HBV, which may spread through the body fluids from a suffering person or through the blood contact or semen from such infected person. It may also be due to the factors below:

- Intimation with different such partners or with the infected person of HBV

- Usage of polluted syringes or needles in medicinal uses

- Homosexuality

- Company or permanent living with someone with the chronic HBV suffered

- Sometimes babies may born from the infected women

- Sometimes people get it who mostly keep in touch with the blood of human or exposed to the blood mostly

- Many areas which are highly polluted like Asia, Eastern Europe and Africa etc. travel in such areas is also another major factor.

\section{Statistics apply infected ratio from HBV in Pakistan}

About seven to nine million people are the carrier of this dangerous virus in accordance with the carrier rate of about three to five percent in Pakistan. This information reviews about its prevailing ratio and its factors, genotype of HBV and the available literature in Pakistan. Almost 106 different studies are included in this study. Proper mentioned graphs are designed for all the population group. The different ratios observed about this HBV are in patient with cirrhosis $28.8 \%$,patient with hepatitis $15.8 \%$,patient with liver disease $27.54 \%$,prisoners $5.75 \%$,pregnant women $5.8 \%$ health care persons $3.2 \%$, ophthalmic patients $3.8 \%$ multiple transfused patients $6.2 \%$ and the user of the drugs like injectable are $14.9 \%$ [12][13].

The major genotype exist and rapidly spreading in Pakistan is genotype D 63\%. On urgent basis, awareness programme should be started in this prevailing HBV population [14].

\section{Major barriers to the prevention and control of $\mathrm{HBV}$}

Deficiency of diagnosis resources and treatment for the suffering people, and proper lack of knowledge of HBV and the major factor is social stigma. The economic crisis of the country leave a bad impact on the public health spending, where investments deficiencies are preventing the proper treatment all around the country . Most people argue that they are always lack of knowledge about HBV from the medical and health centres. Social stigma surrounds the hepatitis B, and also the social discrimination. Not enough education in the community about Hepatitis B and C. Our education about health and hepatitis B in the community still not meet the need of residents. The community health care services have provided with the high blood pressure, heart diseases, and diabetes on daily basis. But the health education about HBV prevention and control are still rare.

\section{Community-based prevention from the liver cancers}

As one million people were dying every year, in 2010, the world Health Assembly invented or introduced an approach, to HBV control of all forms and prevention. This infection is strongly endemic in countries like Asia. And which is going to be a long lasting chronic Hepatitis B which also has complications like life- threatening cirrhosis, hepatocellular cancer in most cases [11].

In Australian men, this chronic Hepatitis B and liver cancer ratio is over two lakh. There in Australia it is detected when it has gone to severe complications level, where there is lack of screening as well for this chronic HBV. In the many comparison were organized. There among the immigrants of south wales- Australia's state suffering HCCs with the individuals which were born in Australia but from china migrants Korea has the greatest ratio of HCCs. There also screening for the chronic HBV is required to improve the treatment, diagnosis education and cure. There are decided some interventions which are multi-pronged to lessen the HBV related liver cancer in the people who are of migrant community. After these all efforts a programme, B positive programme was established which included the education, benefits and primary care from HBV for migrant 
people which was registered.

\section{Conclusion}

There was a clear gap about the awareness of urgent need and demand for the proper health care centres to prevent from the HBV. Social discrimination has limited to get rid of HBV or to prevent from HBV. Lack of qualified staff and very less knowledge publically are other major factors. So the standard treatment, proper diagnosis, and other health services including screening should be managed and enough available in the community. Reduce stigma, provide a solid supported policy and some campaign about it from the GOVT.

Due to people are dying on the ratio like death on road in road traffic injuries ,Diabetes, HIV and AIDS, And even the deaths from other killers like (Malaria, tuberculosis, and HIV) are reduced but the HIV risk is rising up. But this increasing death ratio can be overcome. $95 \%$ immunity is gained by only 3 doses of vaccine of $\mathrm{HBV}$. As it is known it is not properly cured but its treatment can reduce its rising level. It is estimated by WHO that this prevention from higher rising risk will may 7.1 million people by 2030.The prevention and improving cured are prevailing more to improve this ambitious goal for any reduction of risk of disease .Firstly, understand the true ratio of that disease in that society.

\section{References}

[1] Chakvetadze C, Roussin C, Roux J, et al. Efficacy of hepatitis B serovaccination in newborns of African HBsAg positive mothers. Vaccine 2011;29:2846-9.

[2] Hannachi N, Bahri O, Mhalla S, et al. Hépatite virale B chez les femmes enceintes tunisiennes : facteurs de risque et intérêt de l'étude de la réplication virale en cas d'antigène HBe négatif. Pathol Biol 2009;57:e43-7.

[3] Szmuness W. Recent advances in the study of the epidemiology of hepatitis B. Am J Pathol 1975;81:629-50

[4] Parkin DM. The global health burden of infection-associated cancers in the year 2002. Int J Cancer 2006;118:3030-44.

[5] Hainaut P, Boyle P. Curbing the liver cancer epidemic in Africa. Lancet 2008;371:367-8. 12. WHO. Guidelines for the prevention care and treatment of persons with chronic hepatitis B infection, 2015.

[6] Lô G, Diouf NN, Sow Sall A, et al. Prévalence de l'antigène de surface du virus de l'hépatite B au laboratoire de l'hôpital militaire de Ouakam entre 2006 et 2010. Médecine Afr Noire 2014:87-93.

[7] Diop S. Hépatites et Sécurité transfusionnelle au Sénégal. atelier AmBASS du 19 mai 2015;2015.

[8] Ott JJ, Horn J, Krause G, et al. Time trends of chronic HBV infection over prior decades - A global analysis. J Hepatol 2017;66:48-54

[9] Ferrari C, Penna A, Bertoletti A, Valli A, Antoni AD, Giuberti T, et al. Cellular immune response to hepatitis $B$ virus-encoded antigens in acute and chronic hepatitis B virus infection. J Immunol 1990;145:3442-3449.

[10] Bertoletti A, Kennedy PT. The immune tolerant phase of chronic HBV infection: new perspectives on an old concept. Cell Mol Immunol 2015;12:258-263.

[11] Tseng TC, Liu CJ, Yang HC, Su TH, Wang CC, Chen CL, et al. High levels of hepatitis B surface antigen increase risk of hepatocellular carcinoma in patients with low HBV load. Gastroenterology 2012;142:11401149.e3.

[12] Cornberg M, Wong VW, Locarnini S, Brunetto M, Janssen HLA, Chan HL. The role of quantitative hepatitis B surface antigen revisited. J Hepatol 2017;66:398-411.

[13] Fung S, Kwan P, Fabri M, Horban A, Pelemis M, Hann HW, et al. Tenofovir disoproxil fumarate (TDF) vs. emtricitabine (FTC)/TDF in lamivudine resistant hepatitis B: a 5-year randomised study. J Hepatol 2017;66:11-18.

[14] Marcellin P, Ahn SH, Ma X, Caruntu FA, Tak WY, Elkashab M, et al. Study 149 Investigators. Combination of tenofovir disoproxil fumarate and peginterferon alpha-2a increases loss of hepatitis B surface antigen in patients with chronic hepatitis B. Gastroenterology 2016;150:134-144.e10. 